\title{
Basic Contradiction in Religion
}

\author{
Nabil \\ STIT Al Marhalah Al Ulya Bekasi \\ Email: anisbata124@gmail.com
}

\begin{abstract}
Contradiction provide insights into theoritical changes in perspective that lead to multi interpretation the law of contradiction contained unity of opposites in the religion is a fundamental law. And it turns out that there are contradiction in the basic religion of islam, namely syahadat as Ahmad Yulden Erwin in his writing, the contradiction are true and empty is the content.

"No god but God" if the phrase is to be written in symbolic logical language, it will be form into contradiction of proposition; - $p$ a $p$ (which has wrong value). If the phrase is to be written in mathematic language, it will be form; $-1+1$ (which value 0). In other words, "syahadat" is a testimony of contradiction and emptiness. Accordingly the meaning, the phrase on a symbolically logical structure will be value wrong and or empty, except, if and if only. Logic can already prove that the contradiction are true and empty it was none other than content.

Contradiction is the opposite of tautology, which is a form of statement that has only an example of a wrong substance, or a false statement in everything regardless of truth value of it's components. ${ }^{l}$ To prove whether a statement is a contradiction, there are two ways to prove it. First is using a truth table, if all the options are F or false then they are called contradictions. The truth table of $[(p \Rightarrow q) \wedge p] \wedge \sim q$
\end{abstract}

\footnotetext{
${ }^{1}$. Rinaldi Munir, Matematika Diskrit., (Bandung: Informatika, 2005), hlm. 7
} 
Contradiction provide insights into theoritical changes in perspective that lead to multi interpretation the law of contradiction contained unity of opposites in the religion is a fundamental law. And it turns out that there are contradiction in the basic religion of islam, namely syahadat as Ahmad Yulden Erwin in his writing, the contradiction are true and empty is the content.

"No god but God" if the phrase is to be written in symbolic logical language, it will be form into contradiction of proposition; $-p$ a $p$ (which has wrong value). If the phrase is to be written in mathematic language, it will be form; $-1+1$ (which value 0). In other words, "syahadat" is a testimony of contradiction and emptiness. Accordingly the meaning, the phrase on a symbolically logical structure will be value wrong and or empty, except, if and if only. Logic can already prove that the contradiction are true and empty it was none other than content.

Contradiction is not just something that consist outside religion but contradiction consist in it, the law can't be change and hide the contradiction. Even though there is nothing that does not contain contradiction in it, without contradiction there will be no universe.

When religion says "right" don't look the truth just from one point of view (eliminate the contextual or in it). Look at contradiction with contextual (or vice versa). And not impossible, the contradiction will be exist until forever. Basically, religion as vertical (from top to bottom or vice versa) while contextual as horizontal (culture/social). Contradiction means a relationship on the one hand opposed so mutually negated, on the other hand functional means that contradiction will bring forth law transformation to a higher level. The contradiction can't be understood as a schematic or a priori 
dialectic of contradiction. The Contradiction depends on the peculiarities of reality itself and therefore can only be known it the peculiarities are noticed.

In Mao's contradiction, he says that contradiction always be notice from both angle and not just from one angle. For example "religion only and not contextual". Two element of this contradiction noticed, so then an analysis can be precise. ${ }^{2}$

What should be considered in contradiction are: first, contradiction in it (religion and contextual) must be differentiated between main contradiction" and "side contradiction". There are a lot of contradiction in religion or contextual, in general contradiction inside religion itself -mazhab is side contradiction, while contradiction between religion is the main. However side contradiction can become main contradiction or vice versa. Second, in every pair of contradiction both sides are not same, but there is one that have main position and the other is just side position. In general, the contradiction between theory and praxis, between document and argument so there will always be a possibility "which is common in some cases which can be special".

Thus, all religious dogmatism is rejected and the format of law always always proceeds according to the context.

\section{Basic of Contradiction}

Contradiction is the opposite of tautology, which is a form of statement that has only an example of a wrong substance, or a false statement in everything regardless of truth value of it's components. ${ }^{3}$ To prove whether a statement is a contradiction, there are two ways to prove it. First is using a

\footnotetext{
2. Franz Magnis Suseno, Dari Mao ke Marcus, (Jakarta: Gramedia Pustaka Utama, 2013), hlm. 107

${ }^{3}$. Rinaldi Munir, Matematika Diskrit., (Bandung: Informatika, 2005), hlm. 7
} 
Nabil

truth table, if all the options are F or false then they are called contradictions.

The truth table of $[(p \Rightarrow q) \wedge p] \wedge \sim q$ follows ${ }^{4}$ :

\begin{tabular}{|c|c|c|c|c|c|}
\hline P & Q & $\sim q$ & $(p \Rightarrow q)$ & {$[(p \Rightarrow q) \wedge p]$} & $[(p \Rightarrow q)) \wedge p] \wedge \sim q$ \\
\hline B & B & S & B & B & S \\
\hline B & S & B & S & S & S \\
\hline S & B & S & B & S & S \\
\hline S & S & B & B & S & S \\
\hline
\end{tabular}

Always have wrong value (including contradiction) examples of contradiction:

1. $(\mathrm{A} \wedge \sim \mathrm{A})$

Discussion:

\begin{tabular}{|c|c|c|}
\hline $\mathrm{A}$ & $\sim \mathrm{A}$ & $(\mathrm{A} \wedge \sim \mathrm{A})$ \\
\hline $\mathrm{B}$ & $\mathrm{S}$ & $\mathrm{S}$ \\
$\mathrm{S}$ & $\mathrm{B}$ & $\mathrm{S}$ \\
\hline
\end{tabular}

From the truth table above it can concluded that compound statements (A $\wedge \sim \mathrm{A})$ are always wrong.

2. $P \wedge(\sim p \wedge q)$

Discussion:

\begin{tabular}{|c|c|c|c|c|}
\hline P & Q & $\sim p$ & $(\sim p \wedge q)$ & $P \wedge(\sim p \wedge q)$ \\
\hline B & B & S & S & S \\
B & S & S & S & S \\
S & B & B & B & S \\
S & S & B & S & S \\
\hline
\end{tabular}

${ }^{4}$. Lipschutz, Seymour dan George G. hall. 1988. Matematika Hingga,. Jakarta: Penerbit Erlangga. Hlm. 18

-34 -

Al Marhalah : Jurnal Pendidikan Islam. Volume. 2, No. 1 Mei 2018 
This is a truth table that shows a contradiction with the reason that all statements are false $(\mathrm{F})$.

3. $(\mathrm{p} \Rightarrow \mathrm{q}) \wedge \mathrm{p}] \wedge \sim \mathrm{q}$

Discussion:

\begin{tabular}{|c|c|c|c|c|c|}
\hline P & Q & $\sim \mathrm{q}$ & $(\mathrm{p} \Rightarrow \mathrm{q})$ & {$[(\mathrm{p} \Rightarrow \mathrm{q}) \wedge \mathrm{p}]$} & $[(\mathrm{p} \Rightarrow \mathrm{q})) \wedge \mathrm{p}] \wedge \sim \mathrm{q}$ \\
\hline B & B & S & B & B & S \\
\hline B & S & B & S & S & S \\
\hline S & B & S & B & S & S \\
\hline S & S & B & B & S & S \\
\hline
\end{tabular}

Always have wrong value (including contradiction).

4. $\mathrm{q} \wedge(\mathrm{p} \wedge \sim \mathrm{q})$

Discussion:

\begin{tabular}{|c|c|c|c|c|}
\hline P & Q & $\sim \mathrm{q}$ & $\mathrm{p} \wedge \sim \mathrm{q}$ & $\mathrm{q} \wedge(\mathrm{p} \wedge \sim \mathrm{q})$ \\
\hline B & B & S & S & S \\
B & S & B & B & S \\
S & B & S & S & S \\
S & S & B & S & S \\
\hline
\end{tabular}

In the right most column of the table above, it appears that $\mathrm{q} \wedge(\mathrm{p} \wedge \sim \mathrm{q})$ always intends to be wrong for each truth value of it's component. Therefore, the statement $\mathrm{q} \wedge(\mathrm{p} \wedge \sim \mathrm{q})$ is a contradiction.

\section{Lines of Praxis}

When someone asks: is religious argument still can be critized? My answer is: of course, because what can be critized is the argument not the belief. Basically, argument is something that is not absolute. What is forbidden in the religion is exchanging beliefs not exchanging arguments and as scientific truth, religious argument is not afraid by any criticism. 
The core idea of this article is religion as "theory" and contextual as "praxis". The unity between theory and praxis is one of the basic law of epistemology. The question is why we need to start from praxis (contextual)? Human's knowledge begin with sensory capture that captures the outward appearance of reality. When humans in partical activities experience the same impression, then inside human's brain happens a reversal, a leap and created the concepts. The concepts captures the reality of things, their totality and internal connection. Thus, human find something common in special things, internal order, the peculiarities of contradiction, and it means that human understand the reality. So any sense of religion comes from sensory experience but to achieve a religious understanding we can't stop there. At the beginning, religion was a true theory in the objective value, but have not realized as a religious experts. Only in second stage which is praxis, the contextual achieve legal formatting which always goes on.

So the first step is always from praxis to theory but it shouldn't stop at theory. Theory can lead to praxis and therefore contextual basic on the true religion is more effective and more precise. At the same time there is a movement back from praxis (contextual) level two to theory (religion). The application of religion (laws) to the contextual as well as the control over the law itself, which is holy book, whether religious law is correct which mean it's according with the guidance of praxis or know as rahmatan lil 'alamin.

Therefore contextual is the benchmark of the truth of religious law. However it means that religious law can't be considered as something given and fixed. Religion is part of the contradictions intended to be opened and solved by it.

Human's thought toward true religion only comes from contextual. As soon as true ideas penetrate into contextual these ideas become a binding strength between vertical law and horizontal law. We depart from what we -36 -

Al Marhalah : Jurnal Pendidikan Islam. Volume. 2, No. 1 Mei 2018 
have seen to be the core of the praxis line: first, praxis must take precedence over theory. Second the contradiction will be continous. Third, the contradiction is not fixed but continue to shift and change direction (side contradiction can be main contradiction and the main angle can be side angle). From the three core praxis of line it can be deduced that there is not dogmatism.

In praxis, it will be seen whether the theory is right or wrong. Key text reads :

In all true religion law it must always draw from contextual meaning: ijtihad-ijtihad from religious expert must be gathered and concentrated (study and transfer into a concentrated and systematic form) and must be bring back into contextual, clarify until it is fully admit into contextual. Then contextual must be collect again in terms of sociological, cultural, anthropological, psychological, etc. And so the process goes on endlessly, turning incessantly while the ijtihadijtihad becomes more true, alive and richer.

The problem discussed above is the relationship between religion and contextual. It is assumed that how religious law can enter into contextual without removing the existing culture.

\section{Reference}

Munir, Rinaldi, Matematika Diskrit, Bandung: Informatika, 2005

Lipschutz, Seymour dan George G. Hall, Matematika Hingga,. Jakarta: Penerbit Erlangga, 1988

Suseno, Franz Magnis, Dari Mao ke Marcus, Jakarta: Gramedia Pustaka Utama, 2013

Schäfer, Ingo, Mao Tse-tung Eine Einführung in sein Denken, München: Beck, 1999 
Nabil

Scchweppenhäuser, Gerhard, Theodor W. Adorno zur Einführung, Hamburg:

Junius, 2010 